\title{
Resistance to Azole Compounds in ENT and Genital Infections Produced by Candida Species
}

\author{
ELENA RUSU ${ }^{1}$, COSMIN ALEC MOLDOVAN ${ }^{1 *}$, MAGDALENA MIHAELA MITACHE ${ }^{1}$, MIRELA NICULAE ${ }^{2}$, \\ GEORGETA GILDA POPESCU', ROXANA MARIA NEMES ${ }^{1}$ \\ ${ }^{1}$ Faculty of Medicine, University Titu Maiorescu of Bucharest, 67A Gh. Petrascu Str., 031593, Bucharest, Romania \\ ${ }^{2}$ Medicavol, 13 Eroilor Blvd., 077190, Voluntari, Romania
}

\begin{abstract}
Candida albicans species is located in the oral cavity, digestive tract and genital region as the commensal flora in more than half of the healthy population. Infection with species of Candida genus is the most common cause of vaginal infections, second only to bacterial vaginitis. Candida albicans species is ubuquitous commensal yeast that develops in the mucous membranes. Under normal conditions of host health, this microorganism is in balance with the microbiota of these areas but also with the host's immune system. The aim of this study was to determine and compare the sensibility and the resistance of some Candida albicans strains isolated from oro-pharyngeal and vaginal secretions to different azole compunds. In the case of oro-pharyngeal infections, most of the Candida isolated species were resistant to ketoconazole, itraconazole and fluconazole and in the case of isolated species in vaginal infections the resistance was increased in the case of fluconazole, itraconazole and ketoconazole, in different percentages compared to oro-pharyngeal site.
\end{abstract}

Keywords: Candida infection, vaginal, oro-pharyngeal, antifungal agents

Candida (C.) albicans and other Candida species are present in the oral cavity of up to $75 \%$ of the population. In healthy individuals this colonization generally remains benign. However, mildly immunocompromised individuals can frequently suffer from recalcitrant infections of the oral cavity. Such infections are predominantly caused by C. albicans species and can affect the oropharynx and/or the esophagus of persons with dysfunctions of the adaptive immune system [1]. For example, the nicotine influences the biofilm development of oral-associated $C$. albicans ATCC and C. parapsilosis ATCC [2,3].

C. albicans locate in the oral cavity, digestive tract and genital region as the commensal flora in more than half of the healthy population. When given pathogenic opportunity, C. albicans species is responsible for more than $50 \%$ of human candidiasis, including 2 major types of infections, superficial infections (nonlethal), such as oral or vaginal candidiasis and, systemic infections ( $\sim 40 \%$ mortality).

Candida albicans species is ubuquitous commensal yeast that develops in the mucous membranes of the oral cavity, digestive tract and vaginal area. Under normal conditions of host health, this microorganism is in balance with the microbiota of these areas but also with the host's immune system. Because simple changes in the physiology of the human organism can lead to disturbance of the balance in microbiota (favoring the passage of yeast cells from commensalism to parasitism), the Candida genus species exhibit a very high pathogen profile [4]. For this reason, there are a huge number of people who are affected by Candida infections. HIV carriers are the most affected people, as well as patients who have undergone organ transplant, diabetics and patients with low immunity [57]. Factors influencing the expression of virulence characters include environmental factors: composition of the environment, temperature, $\mathrm{pH}$, physiological condition of the host, etc. In addition, in the case of infections an important role is also the type of infection, the nature of the host's response, location and stage of infection.

The most important studies of this yeast have considered the characterization of virulence factors, which are essential in the process of spreading the infection. Analyzing up to the molecular level factors of virulence and pathogenicity can develop a series of strategies to counteract these species with pathogenic potential. The process of development and evolution of microbial infections can be seen as the interaction between the pathogen virulence and the host's ability to prevent or withstand their invasion.

The main factors of pathogenicity and virulence developed by the Candida albicans species are: recognition of surface molecules in the adhesion stage, cellular dimorphism, hyphal formation, production and release of hydrolytic enzymes that degrade different substrates (asparil proteases, phospholipases, lipases, esterases, glucoamylases, acid phosphatases, hemolytic factor) as well as disruption of the immune system activity by inactivating the complement system [8].

Antifungal agents are drugs that have fungicide or fungistatic capabilities, being used in systemic administration, in systemic mycoses or in local application, in localized mycoses, including the oral cavity. Due to the need to combat fungal infections, the study of antifungal substances is in full development and represents an up to date topic.

Azoles exert their action by inhibiting the $C 14 \alpha$ demethylation of lanosterol in fungi, which interferes with the synthesis of ergosterol in the fungal cell membrane. Ergosterol is a key component in fungal cell membrane and similar to human cholesterol. It plays an important role in fungal cell growth. Azoles differ in their affinities to their target, which may account for differences in their spectrum of activity [9]. They are divided into two classes: imidazole which in turn include: ketoconazole (nizoral) and miconazole as well as triazole: fluconazole, itraconazole and voriconazole (fig. 1). These classes of antifungal compounds interact with enzymes thatcatalyze the synthesis of ergosterol in squalene (fig. 2).

In recent years, major fundamental research studies have been conducted to improve our understanding of the molecular basis of antifungal resistance. The fungistatic 


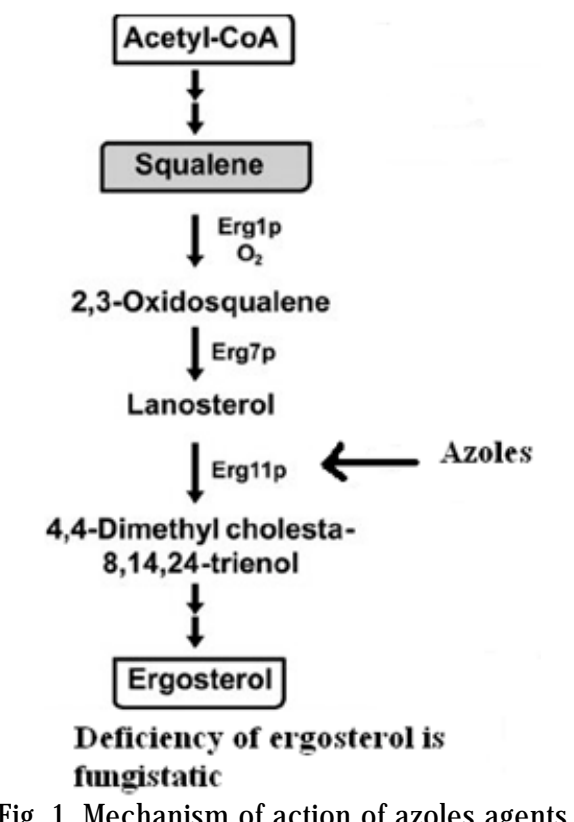

Fig. 1. Mechanism of action of azoles agents

nature and prolonged use of azoles to treat fungal infections, however, has promoted the selection and emergence of drug resistant fungal strains.

The aim of this study was to determine and compare the sensibility and resistance of some Candida albicans strains isolated from oro-pharyngeal and vaginal secretions to different azole compunds.

\section{Experiemntal part}

Our study involves samples of 50 patients, both male and female, selected randomly from the Medicavol Medical Clinic in Bucharest, ENT and Gynecology wards, within a timeframe of 3 months.

\section{Identification of microorganism strains}

After isolating strains from different patients both from oropharyngeal and vaginal secretions, we ended up with the following panel: yeast strains were put into the YPG culture medium (Yeast Peptone Glucose) for $24 \mathrm{~h}$ in aerobic conditions at $150 \mathrm{rpm}$ and $37 \mathrm{p} \mathrm{C}$. The fungal strains have been identified taxonomically according to their morphological and biochemical characteristics [10]. The macroscopic and microscopic characteristics analyzed included the type of colony and cell morphology. Biochemical characterization of yeast strains was performed using the test API Candida system (BioMerieux) and Biolog YT MicroPlate (Biolog System, USA) [11].

\section{Testing the antifungal drug resistance}

In order to test the sensitivity of isolated strains at different azole compounds, the method of disc diffusion for testing of Candida species (CLSI M44-a) was applied, Method for Antifungal Disk Diffusion Susceptibility Testing of Yeasts [12]. The method of disc diffusion test often provides qualitative results $24 \mathrm{~h}$ earlier than the broth solution, which makes testing of antifungal sensitivity more readily available in some clinical laboratories. Direct samples cannot be used in this test. The test should be used with isolated crops. Cultures were made from samples obtained from patients before starting antifungal therapy.

\section{Results and discussions}

Regarding the incidence of the different species of the Candida genus in the types of infections analyzed by us
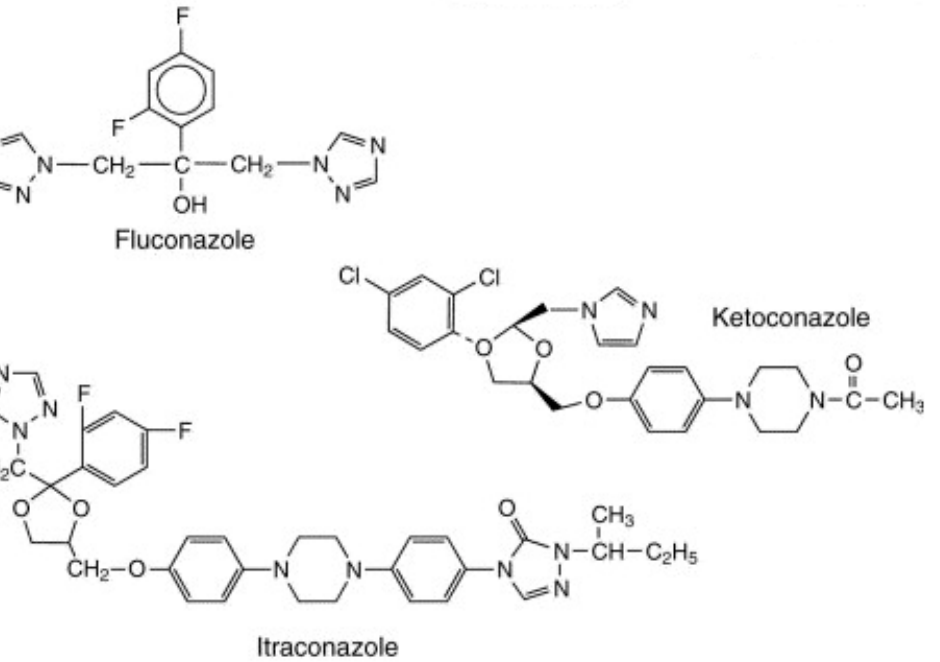

Fig. 2. Chemical structure of azoles

(genital and oropharyngeal), we found that the majority of strains was $C$. albicans species $(90 \%)$, followed by $C$. tropicalisspecies (6\%), C. glabrata (3\%) and C. krusei (1\%) (fig. 3).

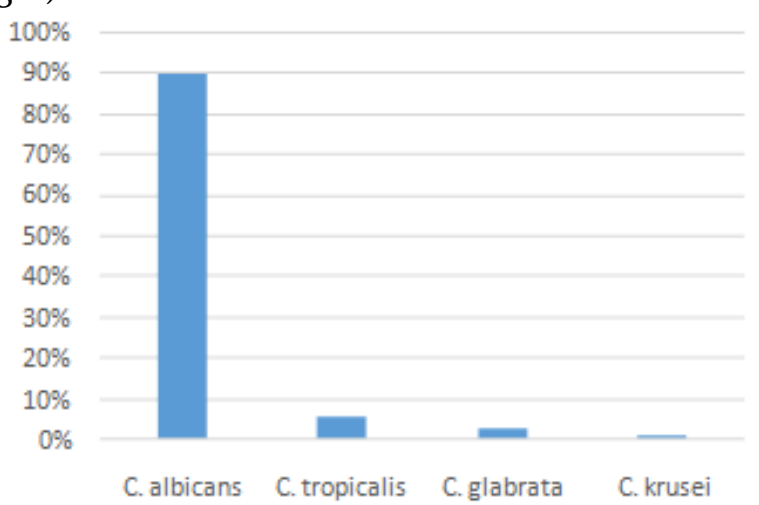

Fig. 3. The incidence of different Candida species in oropharinx and vagina infections

Sensitivity of $C$. albicansstrains isolated in our study from oro-pharyngeal infections, as well as other identified strains of the genus have been tested to determine sensitivity to different azole compounds with antifungal action. The presentation of the resistance of the other strains was carried out for the purpose of comparing the strains of $C$. albicans and non-albicans Candida.

As observed in Table 1, most of the strains of the $C$. albicans species identified by us in oro-pharyngeal secretions are resistant to ketoconazole, fluconazole and itraconazole. In the case of clotrimazole and metronidazole, the analyzed strains showed increased sensitivity (fig. 4).

We also carried out the analysis of the resistance to the antifungal substances of the strains of the Candida genus isolated from vaginal secretions. The obtained results are presented in Table 2. Following our analysis, we found that most tested strains are resistant to fluconazole and itraconazole and susceptible to clotrimazole and metronidazole. As observed comparatively, the resistance of Candida strains varies depending on the location of the infection and is dependent on the strain analyzed.

In the case of oro-pharyngeal infections, most of the species were resistant to ketoconazole, itraconazole and fluconazole (fig. 4) and in the case of isolated species in vaginal infections the resistance was increased in the case of fluconazole, itraconazole and ketoconazole, in different percentages compared to oro-pharyngeal (fig. 5). 


\begin{tabular}{|c|l|l|l|l|l|}
\hline Strain & CLO & MET & KET & FLU & ITR \\
\hline C. albicans 3480 & S & S & R & R & R \\
\hline C. albicans 3450 & $\mathrm{~S}$ & $\mathrm{R}$ & $\mathrm{R}$ & $\mathrm{R}$ & $\mathrm{R}$ \\
\hline C. albicans 3440 & $\mathrm{~S}$ & $\mathrm{I}$ & $\mathrm{R}$ & $\mathrm{R}$ & $\mathrm{R}$ \\
\hline C. albicans 3420 & $\mathrm{~S}$ & $\mathrm{~S}$ & $\mathrm{R}$ & $\mathrm{R}$ & $\mathrm{R}$ \\
\hline C. tropicalis 3320 & $\mathrm{~S}$ & $\mathrm{~S}$ & $\mathrm{R}$ & $\mathrm{R}$ & $\mathrm{R}$ \\
\hline C. tropicalis 3350 & $\mathrm{~S}$ & $\mathrm{~S}$ & $\mathrm{R}$ & $\mathrm{R}$ & $\mathrm{R}$ \\
\hline C. glabrata 3300 & $\mathrm{~S}$ & $\mathrm{~S}$ & $\mathrm{R}$ & $\mathrm{S}$ & $\mathrm{R}$ \\
\hline
\end{tabular}

Tabel 1

THE SENSITIVITY OF CANDIDA STRAINS ISOLATED FROM OROPHARINX TO AZOLE AGENTS

CLO-Clotrimazole, MET-Metronidazole, KET-ketoconazole, FLU-fluconazole,

ITR-itraconazole S- sensitive, R-resistent, I- intermediar

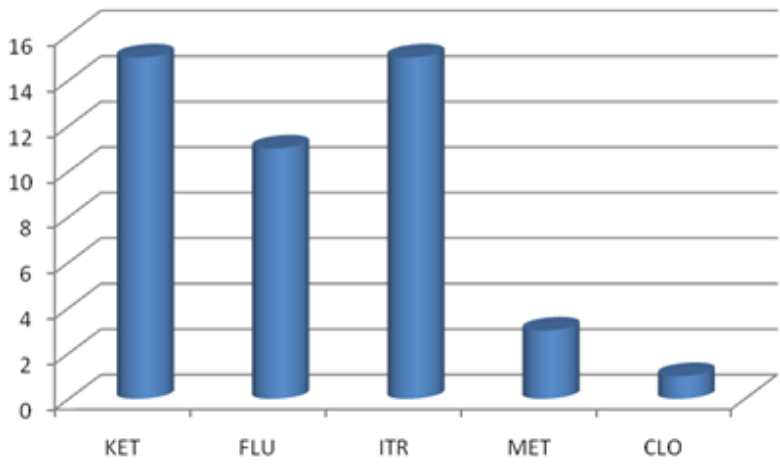

Fig. 4. The resistance of the Candida species isolated from oropharinx samples to different azoles compounds (CLOClotrimazole, MET-Metronidazole, KET-ketoconazole, FLUfluconazole, ITR-itraconazole)

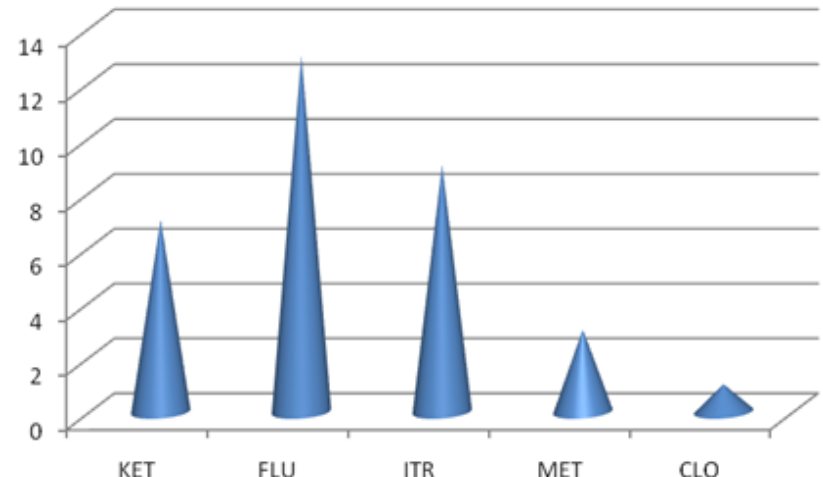

Fig. 5. The resistance of the Candida species isolated from vagina samples to different azoles compounds

(CLO-Clotrimazole, MET-Metronidazole, KET-ketoconazole, FLUfluconazole, ITR-itraconazole)

\begin{tabular}{|c|l|l|l|l|l|}
\hline Strain & CLO & MET & KET & FLU & ITR \\
\hline C. albicans 139V & S & R & S & I & R \\
\hline C. albicans 178V & S & S & R & R & S \\
\hline C. albicans 088V & R & R & R & R & R \\
\hline C. albicans $733 \mathrm{~V}$ & S & S & S & R & R \\
\hline C. albicans 961V & S & R & S & R & S \\
\hline C. albicans 512 V & S & S & S & S & S \\
\hline C. albicans 155V & S & S & R & R & R \\
\hline C. albicans 183 V & S & R & R & R & R \\
\hline
\end{tabular}

Tabel 2

THE SENSITIVITY OF CANDIDA STRAINS ISOLATED FROM VAGINA SAMPLESTO AZOLE AGENTS

ITR-itraconazole, S- sensitive, R-resistent, I- intermediar

Some species of fungi are naturally resistant to different types of antifungal medication. Other species may normally be susceptible to a particular type of medication but may develop resistance over time as a result of improper use, for example using an inappropriate dosage, which may be too low, or the duration of treatment that is not long enough $[13,14]$.
Other studies have shown that antibacterial medication can also contribute to antifungal resistance. This can happen for a number of reasons, one referring to the fact that antimicrobials reduce bacterial species from microbial flora and create favorable conditions for the growth of Candida species [15, 16]. 
If vaginal infections are not detected and treated in time, complications may occur, such as: infertility, premature births, premature rupture of the membranes, intra-amniotic infections, endometriosis, intra-epithelial cervical cancer as well as post-operative gynecological infections. At present, it is believed that the pathogenesis and recurrence of vaginal candidiasis are related to many factors, such as the increasing resistance of Candida, the local immune response of host against Candida, and the change of virulence factor of Candida.

A range of environmental factors affect $C$. albicans morphology. For example, atlow $\mathrm{pH}(<6) \mathrm{C}$. albicanscells predominantly grow in the yeast form, while at a high $\mathrm{pH}$ (> 7) hyphal growth is induced. Indeed, a number of conditions, including starvation, the presence of serum or $\mathrm{N}$-acetylglucosamine, physiological temperature and $\mathrm{CO}_{2}$ promote the formation of hyphae. Morphogenesis has also been shown to be regulated by quorum sensing, a mechanism of microbial communication.

Ergosterol is a bio adjuster and regulator of membrane fluidity and is the major sterol of fungal membranes; it is essential for developmental growth and the main target of antifungals that are currently used to treat fatal fungal infections. It has been demonstrated that mutations in ERG11, the gene encoding for the target enzyme lanosterol $\mathrm{C} 14 \alpha$-demethylase, prevents binding of azoles to the enzymatic site. This enzyme catalyzes the transformation of lanosterol into ergosterol. Triazole compounds (fluconazole, itraconazole, voriconazole and parconazole) binds to the hem group of the target enzyme and blocks the lanosterol demethylation at $\mathrm{C}-14$ which has the effect of ergosterol depletion and accumulation of intermediate toxic sterols [17].

Nowadays, the most important problem is raising drug resistance. Fungistatic rather than fungicidal activity of azole drugs leads to the frequent emergence infections caused by azole-resistant Candida sp. In the case of Candida species infections, have been described four major mechanisms of resistance to azoles: more than 1 mechanism can be functioning in any given fungal strain with additive effects. These major mechanisms are: decreased drug concentration, target site alteration, upregulation of target enzyme and, development of bypass pathways [18].

C. albicans express several virulence factors that contribute to its pathogenicity. These factors include environmental adaptation factors, adhesins, morphogenesis, secreted enzymes, phenotype switching, and biofilms. The species of the Candida genus are responsible for vulvovaginal candidosis (VVC) (even 25\% of vulvovaginal infections). Predominantyeasts are Candida albicans, Candida glabrata and Candida tropicalis species. The incidence of infection affects $70-75 \%$ of women. Women carry Candidamicrorganisms in the vagina without symptoms or signs of vaginitis, because of the balance between pathological effects and vaginal defense factors [19]. Infection with species of Candida genus is the most common cause of vaginal infections, second only to bacterial vaginitis. Candida has a high rate of intravaginal colonization; it can be isolated from the vagina of about $20 \%$ of healthy asymptomatic women and $30 \%$ of pregnant women.

At the genitourinary-urinary tract we can find: vulvovaginal candidiasis (second cause of vaginitis), pyelonephritis Candida (favored by diabetes mellitus and the presence of stents or other surgical devices at the renal level) as well as asymptomatic candiduria - that occurs especially in probed patients and the difficulty consists in distinguishing a colonization from an invasion, because about $5-10 \%$ of all urinary cultures are positive for Candida.

In recent years, due to the increased resistance of many bacterial and fungal species to the commonly used antimicrobial agents, attention has shifted to drugs belonging to different pharmacological classes for their possible antimicrobial activity [20]. This, borne out of the fact that a single drugs may have varying properties with diverse physiological activities and functions and may have useful activities in different spheres of medicine [21, 22].

In the last years, some researchers suggested that prostaglandins can be viewed as regulators of $C$. albicans virulence because the eicosanoids pathway in $C$. albicans species plays a central role in the control of morphogenesis and biofilm formation. As a consequence, they further suggested that the development of drugs that specifically target the fungal prostaglandins pathways may be one strategy to combat fungal colonization and infection.

For example, sodium diclofenac can achieve an inhibition of phospholipase A2, as part of mechanism of action. Phospholipases A2 and B have been identified in a large number of pathogenic eukaryotic organisms such as the species $C$. albicans, Cryptococcus neoformans and Aspergillus fumigatus. These phospholipases catalyze the cleavage of fatty acids chains in the phospholipid structure. They are considered as virulence factors of many pathogenic species, including $C$. albicans, by destroying the cell membrane of the host cell [23-25]

\section{Conclusions}

In the case of oro-pharyngeal infections, most of the Candida isolated species were resistant to ketoconazole, itraconazole and fluconazole and in the case of isolated species in vaginal infections the resistance was increased in the case of fluconazole, itraconazole and ketoconazole, in different percentages compared to oro-pharyngeal site.

Some species of fungi are naturally resistant to different types of antifungal medication. Other species may normally be susceptible to a particular type of medication but may develop resistance over time as a result of improper use of the specific medication.

\section{References}

1.MAYER, FL., WILSON, D., HUBE, B., Virulence, 4, nr. 2, 2013, p. 119 2.GUNASEGAR S, HIMRATUL-AZNITA WH., FEMS Yeast Res., 2018, doi: 10.1093/femsyr/foy123.

3.IANOSI, E.S., DANTES, E., CSIPOR, A., SZATHMARY, M., SOCACl, A., RUSU, E., NEMES, R.M., Rev Chim (Bucharest), 69, no. 10, 2018, p. 2725

4.LU, Y., SU, C., LIU, H., Trends Microbiol., 22, nr. 12, 2014, p.707 5.CRISTESCU, C., RUSU, E., CRISTESCU, V., BERCA, LM, NICULAE, OM., CIMPONERIU, D., SPANDOLE, S., TOMA, E., CRACIUN, AM., SERAFINCEANU, C.. Rom. Biotech. Lett., 19, nr. 5, 2014, p. 9678 6.POSTOLACHE, P., NEMES, RM., PETRESCU, O., ET AL., MedicalSurgical J .- Rev. Medico-Chirurgicala, 119, nr. 1, 2015, p.77

7.NITU, FM., OLTEANU, M., STREBA, CT., JIMBOREAN, G., POSTOLACHE, P, MAN, MA., TROFOR, AC., NEMES RM., DRAGONU L., OLTEANU M., Rom. J. Morphol. Embryol., 58, nr. 2, 2017, p.385 8.SARBU, I., PELINESCU, D., STOICA, I., MARUTESCU, L., VASSU, T., Rom. Arch. Microbiol. Immunol., 72, nr. 4, 2013, p. 225

9.ROBBINS, N., CAPLAN, T., COWEN, LE., Annu. Rev. Microbiol., 8, nr. 71, 2017, p.753

10.RUSU, E., ENACHE-SOARE, S., PELINESCU, D. SARBU, I., COJOCARU, M., VASSU, T., Rom. Biotech. Lett., 20, nr. 4, 2015, p.10585 11.RUSU, E., EPURAN, S., CRISTESCU, C., COJOCARU, M., Rom. J. Infect. Dis., XVII, nr.1, 2014, p.25

12.*** CLINICAL AND LABORATORY STANDARD INSTITUTE, M44-A2, 29, nr. 17, 2009, https://clsi.org/media/1634/m44a2_sample.pdf 
13.LORTHOLARY, O., DESNOS-OLLIVIER, M., SITBON, K, ET AL. Antimicrob. Agents Chemother., 55, nr. 2 , 2011, p. 532

14.SHAH, DN., ZAU, R., LASCO, TM., ET AL. Antimicrob. Agents Chemother., 56, nr. 6, 2012, p. 3239

15.BEN-AMIR, R., OLSHTAIN-POPS, K., KRIEGER, M., ET AL. Antimicrob. Agents Chemother., 56, nr. 5, 2012, p. 2518

16.MITACHE, M.M., CUTUTIU, C., RUSU, E., BAHNA, R., DITU, M., MOLDOVAN, H., HANCU, V., CHIFIRIUC, M.C., Rev. Chim. (Bucharest), 68, no. 3, 2017, p.566

17.COWEN, LE., STEINBACH, WJ., Euk. Cell., 7, nr. 5, 2008, p. 747

18.KANAFANI, ZA., PERFECT, JR., Clin. Infec. Dis., 46, nr. 1, 2008, p. 120

19.PORADZK, A., JASIK, M., KARNAFEL, W., FIEDOR, P. Acta Poloniae Pharmaceutica- Drug Research, 70, nr. 4, 2013, p. 587
20.TANTU, M.M., MAN, G.M., PAUNESCU, A., PLESA, C.F., NEMES, R.M., NICOLAE, C.M., ROGOZEA, L.M., MOLDOVAN, C., RUSU, E., BISOC, A., Rev. Chim. (Bucharest), 69, 2018, no. 11, p. 3001

21.RUSU, E., RADU-POPESCU, M., PELINESCU, D. VASSU, T., Braz. J. Microbiol., 45, nr. 4, 2014, p.1379

22.RUSU, E., SARBU, I., CRISTESCU, C., COCULESCU, B., MOLDOVAN, H., PETRUT, S., MURESAN, A., VASSU, T., PELINESCU, D., Rev Chim (Bucharest), 67, no.12, 2016, p. 2417

23.RUSU, E., SARBU, I., MITACHE, M., MOLDOVAN, H., VASSU, T., PELINESCU, D. Rev Chim (Bucharest), 68, no. 11, 2017, p. 2566 24.SIRBU, I., PELINESCU, D., IONESCU, R., DASCALU, L., ALEXANDRU, I., CHIFIRIUC, C., RUSU, E., NEDELCU, I., VASSU, T., Farmacia, 64, nr. 2, 2016, p.274

25.RUSU, E., ENACHE-SOARE, S., CREANGA, O., VASSU, T., Rom. Biotech. Lett., 14, nr. 5, 2009, p. 4720

Manuscript received: 14.08 .2018 